\title{
Vigilância popular da saúde nas comunidades pesqueiras tradicionais e ecologia dos saberes no enfrentamento à COVID-19
}

\author{
Popular health surveillance in traditional fishing communities \\ and the ecology of knowledges in the fight against COVID-19
}

\begin{abstract}
Ana Angélica Martins da Trindade (https://orcid.org/0000-0002-9743-0212) ${ }^{1}$ Paulo Gilvane Lopes Pena (https://orcid.org/0000-0001-9653-5509) ${ }^{1}$

Mônica Angelim Gomes de Lima (https://orcid.org/0000-0003-3364-8439) ${ }^{1}$

Maria do Carmo Soares de Freitas (https://orcid.org/0000-0002-8310-0933) ${ }^{1}$

Kênya Lima de Araújo (https://orcid.org/0000-0001-9913-7485) ${ }^{1}$
\end{abstract}

${ }^{1}$ Programa de PósGraduação em Saúde Ambiente e Trabalho, Faculdade de Medicina da Bahia, Universidade Federal da Bahia. Av. Reitor Miguel Calmon s/n, Vale do Canela, 40110-100. Salvador BA Brasil. angelica.ana@ufba.br
Abstract Considering the public health emergency of international importance caused by COVID-19, artisanal fishing workers, engaging in a dialogue with Brazilian leaders and scholars, created an Observatory on the impacts of this pandemic on fishing communities in March 2020. The purpose of this article is to analyze the experience of popular surveillance of fishermen and fisherwomen's health through daily reports produced at the Observatory. It is a monitoring process that allowed broadening the recognition of the diversity of vulnerable populations' ways of life that intertwine health, environment and work. The study used a qualitative, horizontal and emancipatory methodology and sought approaches to the practice of the ecology of knowledges, with the following results: shared construction of information and knowledges based on heterogeneous social experiences; practice of collective ombudsman with the appreciation of knowledges built in social struggles); joint assessment of public health inequities, territorial conflicts, and environmental, structural, and institutional racism; guidance of social leaders and fundraising through public notices. Thus, the dynamics and horizontality of learning based on solidarity and social emancipation from inter-knowledge are revealed.

Key words Health, COVID-19, Surveillance, Fishing
Resumo Diante da emergência em saúde pública de importância internacional provocada pela COVID-19, trabalhadores da pesca artesanal, em diálogo com lideranças e acadêmicos brasileiros criaram, em março de 2020, um Observatório sobre os impactos dessa pandemia em comunidades pesqueiras. $O$ objetivo deste artigo é analisar a experiência de vigilância popular da saúde de pescadores e pescadoras através de boletins diários produzidos no Observatório. Trata-se de um processo de monitoramento que possibilitou ampliar o reconhecimento da diversidade de modos de vida das populações vulneráveis que entrelaça saúde, ambiente e trabalho. O estudo utilizou metodologia qualitativa, horizontal e emancipatória e buscou aproximações à prática da ecologia dos saberes, tendo como resultados: construção compartilhada de informações e conhecimentos com base em experiências sociais heterogêneas; prática da ouvidoria coletiva com a valorização de saberes construídos nas lutas sociais; avaliação conjunta de iniquidades em saúde pública, conflitos territoriais e racismo ambiental, estrutural e institucional; orientação das lideranças sociais e captação de recursos através de editais públicos. Revela-se, assim, dinamicidade e horizontalidade de aprendizados com base na solidariedade e emancipação social a partir do interconhecimento.

Palavras-chave Saúde, COVID-19, Vigilância, Pesca 


\section{Introdução}

A COVID-19 é uma doença infecciosa caracterizada como Síndrome Respiratória Aguda Grave Coronavírus (Sars-CoV-2) na sua forma grave, identificada em dezembro de 2019 na China, com rápida propagação pelo mundo e que gerou uma das maiores crises sociossanitárias da modernidade. Até 14 de maio de 2020 eram 4.248.389 contaminados e 294.046 mortes no mundo. A Organização Mundial da Saúde (OMS) declarou o surto como pandemia exigindo respostas rápidas dos países e de autoridades sanitárias internacionais ${ }^{1-3}$.

A OMS recomendou um conjunto de estratégias de saúde pública, tanto para a prevenção da propagação da COVID-19 como para a diminuição da sobrecarga dos sistemas de saúde, inclusive, sua forma mais rígida, o lockdown, ou seja, o distanciamento social restrito com bloqueio total ou parcial de circulação, incluindo barreiras sanitárias e redução dos contatos entre as pessoas ${ }^{4}$. O Brasil é um país com histórico de colonialismo que, além da grave crise sanitária temporária da COVID-19, enfrenta tensões permanentes, políticas e econômicas, com agravamento das vulnerabilidades sociais. Isso provoca, especialmente, a incapacidade do sistema de saúde pública de se manter como projeto social de transformação social com superação das iniquidades em saúde, consideradas desnecessárias, evitáveis e injustas.

Segundo Santos 5 , o colonialismo é um modo de dominação moderna que se impõe através da invasão de territórios e submissão de povos por razões étnico-raciais, praticada por grupos econômica e politicamente dominantes, tidos como "conquistadores". Mantém-se até a atualidade, assumindo novas formas como o colonialismo interno ou neocolonialismo. Uma das principais estratégias se dá com o estabelecimento institucional de estruturas de poder colonial responsáveis pela reprodução de variadas práticas de violências, como racismo, especulação imobiliária, expulsão de terras, megamineração, tráfico, trabalho escravo, entre outras. Concretizam, assim, as chamadas zonas de não-ser sustentadas em privilégios sociais consequentes da expropriação da dignidade humana.

As atuais condições de vida e de trabalho da maioria das pessoas tornam o Brasil o segundo maior concentrador de renda do mundo, atrás apenas do Catar, tendo como consequência a expansão da pobreza absoluta ${ }^{6}$. Segundo a Pesquisa Nacional por Amostras de Domicílios (PNAD), em 2019, a média do rendimento mensal de $1 \%$ da população brasileira é de 33,8 vezes maior do que a renda dos 50\% mais pobres da população ${ }^{7}$. Desempregados há mais de dois anos passaram de $17,4 \%$ (2015) para $24,8 \%$ (2019), um total de 3,3 milhões de pessoas ${ }^{8}$.

A população afrodescendente é, historicamente, a mais atingida, por estar mais exposta às práticas de racismo e colonialidade que se sobrepõem ao assumir formas estruturais, institucionais e ambientais, intensificadas em contextos pandêmicos. A propagação do novo coronavírus segue a trajetória das desigualdades sociais, a exemplo de uma das primeiras vítimas registradas no Brasil, uma mulher negra, 63 anos, trabalhadora doméstica, contaminada pela empregadora que ao ser diagnosticada com a doença, não impediu o risco de contaminação. Pessoas pretas, pardas e pobres passaram a morrer mais, somando $51,3 \%$ dos óbitos pela doença, ao passo que as brancas foram $46,5 \%$. Entretanto, estas ingressaram mais nos hospitais com $54,8 \%$ ante $43 \%$ do primeiro grupo'.

O Sistema Único de Saúde (SUS), estrutura da saúde pública nacional desde 1990, assumiu o dever do Estado junto aos movimentos sociais, o compromisso com a recuperação, proteção e promoção da saúde de toda a população. Na atualidade, mais de $70 \%$ do povo brasileiro depende exclusivamente do SUS, entretanto, o subfinanciamento desidratou a proposta restringindo a capacidade de respostas à pandemia, especialmente às populações em condições de insegurança social ${ }^{10}$.

No acompanhamento inicial da propagação da COVID-19, o Sistema de Vigilância do SUS se destacou com a produção de estratégicas de informações para orientar meios de mitigação da transmissão, bem como prevenir mortes subsequentes. E, evidenciou a necessidade da melhoria da relação entre vigilância e saúde em tempos de crise. Mas, a partir de maio, o governo federal alterou informações sobre a expansão da doença no país, dificultando o enfrentamento do problema e confundindo a população sobre a gravidade dessa pandemia.

Este artigo analisou a prática de vigilância popular da saúde (VPS) de comunidades pesqueiras na convivência com a COVID-19, considerando, por um lado, as consequências das desigualdades sociais, agravadas pela pandemia, em diferentes cenários do país e com ameaças cotidianas à existência. Por outro, considerou-se o enfrentamento da crise sanitária a partir dos saberes produzidos nas lutas sociais e políticas.

Os trabalhadores da pesca artesanal são os sujeitos deste estudo e representam a hetero- 
geneidade das populações das águas: praieiros, jangadeiros, caiçaras, quilombolas, indígenas, açorianos de diferentes regiões do Brasil. Em geral, são trabalhadores pobres e não-assalariados que dependem da labuta diária, em que muitos contam, apenas, com a pesca para a subsistência. Segundo os cadastrados do Ministério da Agricultura, Pecuária e Abastecimento / Secretaria de Aquicultura e Pesca, em 2011, havia um milhão e 41 mil pescadores registrados, sendo que $99 \%$ deste total eram artesanais e distribuídos pelas regiões do país da seguinte forma: $54,7 \%$ no Nordeste, $45 \%$ no Norte, $10 \%$ no Sudeste, $7,5 \%$ no Sul e 2,2 \% no Centro-Oeste ${ }^{11}$.

Em termos de trabalho, muitos são os pescadores e pescadoras que se desgastam nas atividades de trabalho de forma grave, expõem-se a riscos diversificados de agravos, doenças e acidentes de trabalho. São invisíveis à vigilância em saúde e, praticamente, não dispõem de garantias de proteção social ou mesmo segurança alimentar e nutricional.

A atividade pesqueira é ainda constitutiva da culturalidade nacional, estabelece um modo de vida e de sociabilidade, envolve saberes dos povos das águas transmitidos de geração a geração; orientam-se pela solidariedade comunitária e ancestralidades que transcendem para territórios. Estudos como os de Pena e Martins ${ }^{12}$ e Callou ${ }^{13}$ atentam para a dívida social do país com esses trabalhadores das águas, submetidos historicamente a condições sociais de dominação que comprometem o bem viver.

O objetivo do estudo foi acompanhar pescadores e pescadoras brasileiras no que diz respeito à vigilância popular da COVID-19 em suas comunidades, tendo em vista processos de produção de informações e conhecimentos emancipatórios com possibilidade de vivenciar a ecologia dos saberes na superação dos desafios trazidos pela pandemia.

\section{Metodologia}

O estudo em tela insere-se no campo da Saúde Coletiva/Saúde Pública e é de natureza qualitativa, horizontal e emancipatória ${ }^{14,15}$, voltado para análise de boletins de vigilância popular da COVID-19 de comunidades pesqueiras. Para Minayo $^{15}$, a pesquisa qualitativa permite a compreensão em profundidade da experiência social, exige um conhecimento teórico, empírico e relacional que aproxima, de maneira indissociável, teoria e metodologia, bem como recorre a aspec- tos históricos, significados, crenças, valores, práticas e saberes dos diferentes atores sociais.

De forma complementar, Berkin e Kaltmeier ${ }^{16}$ se referem à metodologia qualitativa do tipo horizontal como um meio para estabelecer diálogos entre sujeitos sociais; uma espécie de intercâmbio com base na horizontalidade e reciprocidade entre pesquisadores e seus interlocutores, compreendidos como portadores de conhecimentos variados e protagonistas de suas histórias. A produção de conhecimento é assumida como um compromisso político, baseada em teorias, práxis, métodos, experiências.

Nesse sentido, buscou-se contribuir com a discussão sobre vigilância popular da saúde a partir da análise dos informativos, aqui chamados de boletins, produzidos de forma coletiva e colaborativa, com base em narrativas livres de diferentes atores sociais da pesca artesanal e acadêmicos, dos diversos estados brasileiros, em interação na rede social. A proposta voltou-se para o exercício da ecologia dos saberes que, segundo Santos ${ }^{17}$, aponta para construções coletivas de aprendizados a partir da relação entre sujeitos plurais, como: acadêmicos, lideranças sociais e trabalhadores da pesca artesanal, visando a intersubjetividade e o interconhecimento. Estabelecem-se assim diálogos que valorizam a heterogeneidade e a autonomia de saberes e práticas sociais.

A partir de um espaço virtual os participantes publicaram mensagens em diferentes formatos como textos, áudios, imagens, relatos e informativos técnicos jurídicos e de saúde, relacionados à COVID-19 que subsidiaram a elaboração dos boletins. Das mensagens, destacaram-se categorias das expressões significantes para a compreensão dos textos. Construiu-se, assim, as seguintes categorias de análise: pautas para os movimentos sociais, ações governamentais, comunitárias e auxílio emergencial. Foram analisadas mensagens produzidas no período de 21 de março a 31 de maio de 2020 (compartilhadas duas vezes ao dia com o grupo). O estudo interpretativo revelou a compreensão dos complexos efeitos do adoecimento em pescadores e pescadoras.

A investigação teve aprovação do Comitê de Ética em Pesquisa da Faculdade de Medicina da Universidade Federal da Bahia.

\section{Resultados e discussões}

O Observatório dos Impactos da COVID-19 em comunidades pesqueiras foi criado em $17 \mathrm{de}$ 
março de 2020, por lideranças sociais e acadêmicos com o intuito de contribuir com a preparação dos povos e territórios pesqueiros tradicionais para o enfrentamento da pandemia.

Um grupo de interação na rede social por meio da plataforma WhatsApp reuniu pescadores e pescadoras artesanais, lideranças de movimentos pesqueiros, pesquisadores e estudantes de diferentes estados do Brasil. São cinco movimentos sociais representados no grupo: Comissão Pastoral da Pesca; Movimento de Pescadoras e Pescadores Artesanais do Brasil; Comissão Nacional de Fortalecimento das Reservas Extrativistas e Povos e Comunidades Tradicionais Extrativistas Costeiras e Marinhas; Articulação Nacional das Pescadoras; e Coordenação Nacional de Comunidades Tradicionais Caiçaras. Os acadêmicos são oriundos de cinco Universidades Federais: Paraná, Pernambuco, Recôncavo Baiano, Bahia e Pará.

Até 25 de maio, eram 179 participantes representantes de 23 estados brasileiros, o que caracterizou a abrangência nacional e expressiva participação no Observatório, com ocorrências de postagens que passaram de 293 em março para 567 em abril. Na plataforma são compartilhadas reflexões e ações com propostas de resolução dos problemas que afetam as comunidades quanto à COVID-19.

A gestão coletiva se destaca ainda como mobilizadora da relação entre saberes diversos, tradicionais e acadêmicos, e uso de tecnologias. Informativos, ações, projetos, documentos são produzidos de forma participativa, com base na troca de ideias entre pescadores, vigilantes populares, e pesquisadores conforme sugere a ecologia dos saberes ${ }^{17}$. Por Santos, analisou-se a realidade social de forma crítica, dinâmica e colaborativa, partindo dos aprendizados advindos das lutas e resistência populares em defesa da saúde que visam superar iniquidades, com protagonismo dos pescadores e das marisqueiras deste Observatório ao engajarem-se no autoconhecimento, na integração com o ambiente, na organização da luta política e na sistematização dos seus saberes e metodologias, logo buscam enfrentar os desafios sanitários que historicamente impediram o bem viver.

O diálogo entre saberes científicos e populares se materializa na produção dos boletins de VPS e analisados neste estudo. Os boletins registram resumidamente o cenário da pandemia de COVID-19 nas comunidades tradicionais pesqueiras de diferentes lugares do Brasil e são compartilhados diariamente em dois momen- tos: primeiro, por volta das 19 horas, em formato provisório, para que em um período de duas horas os participantes apresentem suas contribuições; em seguida, publica-se a versão definitiva. Os informativos diários descrevem conteúdo das mensagens do Observatório, retomados mensalmente em boletins analíticos. Até o dia 31 de maio, produziram-se 72 informativos diários e três mensais.

O boletim é composto por quatro categorias de análise que emergiram das postagens livres, a saber: 1) pautas para os movimentos sociais, 2) ações governamentais, 3) ações comunitárias e 4) auxílio emergencial. Em Pautas destaca temas importantes para a ampliação da organização dos movimentos sociais pesqueiros, revela necessidades singulares e diversas do grupo e de seus territórios, com destaque para pluralidades históricas e culturais, relacionadas à identidade coletiva. Aspectos que dialogam com a perspectiva da emancipação social defendida por Boaventura Santos, que considera as contradições sociais reveladas pelas vulnerabilidades sociais, reforçadas pelos sistemas de produção do conhecimento, típicos da modernidade, que dificultam a aproximação entre teorias e práticas sociais com menosprezo aos saberes tradicionais dos povos das águas.

As pautas revelam inúmeras ameaças cotidianas à dignidade dos povos das águas, principalmente, em termos de direitos sociais, evidenciadas ainda mais com a pandemia. A maior parte das postagens (838 de um total de 1.259) direciona-se a essa categoria e revela efeitos da COVID-19 para as comunidades tradicionais e seus trabalhadores, como a desproteção social, fragilidade da saúde pública, negação da cidadania, além do aumento de notícias falsas e dos conflitos aos quais essas populações estão submetidas, aspectos estes que se tornaram mais complexos ao longo dos meses analisados.

No mês de março os participantes revelaram históricas trajetórias de luta pelo reconhecimento de pescadores artesanais como trabalhadores não-assalariados. Com a expansão da COVID-19, preservar a vida exige a garantia do direito à quarentena acompanhada de proteção social.

Os pescadores denunciaram a irregularidade no repasse de benefícios sociais em determinados períodos, como o Seguro-Defeso, permanente e específico para o pescador artesanal. Outro benefício citado como irregular, apesar de seu caráter temporário, foi o Auxílio-Óleo, destinado aos trabalhadores atingidos em setembro de 2019 pelo derramamento de petróleo, especialmente, 
no litoral do Nordeste brasileiro. Essa tragédia desencadeou uma crise socioambiental com prejuízos de renda e danos à saúde das comunidades pesqueiras, sem contar a contaminação ambiental.

O Registro Geral da Pesca (RGP) foi apontado como meio de reconhecimento legal do pescador artesanal como trabalhador, entretanto, mantém-se desatualizado e não contempla parte desta população, especialmente, os idosos, dificultando acesso aos direitos trabalhistas.

A plataforma do Observatório possibilitou iniciativas comunitárias, como a oferta do produto através das redes sociais, entrega a domicílio, e negociações com prefeituras locais para a compra do pescado como item de cesta básica. A partir de maio, os trabalhadores da pesca foram condicionados a voltar ao trabalho, pois não contaram com proteção social suficiente, $\mathrm{e}$ assumiram os riscos de contaminação diante da insegurança alimentar e social.

Com a orientação do Observatório, houve o incentivo à produção em grupos menores, mantendo distância entre os barcos e com uso de máscaras. Entretanto, outros observatórios de saúde no Amazonas denunciaram embarcações com aglomerações de passageiros no deslocamento fluvial intermunicipal como meio de difusão do novo coronavírus ${ }^{18}$.

As fakes news relacionadas à COVID-19 também preocuparam os membros do Observatório durante os meses analisados, pelo fluxo intenso de informações falsas entre comunidades pesqueiras que provocou desinformação e confusão. As interações no Observatório, propiciaram posturas educativas para qualificar a confiabilidade das notícias e reconhecer a manipulação de informações. Assim, a orientação para a ecologia de saberes revelou possibilidades de enfrentar problemas a partir do interconhecimento e da interculturalidade que possibilitam análises $\mathrm{e}$ reflexões compartilhadas, sistematização de experiências sociais e construções coletivas para responder às necessidades tanto singulares, como heterogêneas das comunidades pesqueiras. Estabelece-se espaço de diálogo, monitoramento e denúncias, inclusive, das notícias falsas que provocam desinformação, e com capacidade de fortalecer referências de confiança, mobilização política e participação social.

A necessidade de proteger as comunidades tradicionais diante dos conflitos frequentes, especialmente territoriais e exacerbados com a pandemia, torna-se tema relevante para o grupo. Com o avanço da doença no interior do país, in- dígenas aldeados, populações ribeirinhas e quilombolas em comunidades isoladas são progressivamente afetados. Relatos revelam a violência de práticas de racismo institucional, injustiças ambientais e sociais que ameaçam a existência, a dignidade e a vida dos povos e de seus territórios das águas.

Durante o mês de abril, turistas e veranistas desrespeitaram medidas de isolamento em territórios pesqueiros, desrespeitaram populações locais, praticaram pesca predatória, ignoraram barreiras sanitárias comunitárias, lotaram praias, mesmo diante da precariedade dos serviços de saúde locais. Os turistas exacerbam posturas individualistas, consideram-se em período de férias. Maio ocorreu o aumento de relatos sobre a chegada de ônibus até mesmo clandestinos em localidades, alguns com pessoas doentes. Houve, ainda, denúncias de invasões em terras indígenas e territórios quilombolas ameaçados pelos interesses de demarcação dos lugares tradicionais e expulsão de seus povos originários.

Os fatos sugerem insuficiência das medidas governamentais e explicitaram o desrespeito à articulação da comunidade local em relação às tentativas de proteção contra a COVID-19, revelando, assim, a não-existência de um tecido social solidário.

A proteção ao trabalhador, o direito à informação e o respeito aos povos tradicionais são questões de saúde. Entretanto, relatos dos pescadores apontaram aspectos negativos diretamente relacionados aos serviços de saúde, como fragilidades de orientações preventivas e de infraestrutura, muitas delas anteriores à pandemia.

Em abril, a ênfase nas regiões Nordeste e Sudeste foi a necessidade de barreiras sanitárias, acesso aos serviços, além dos problemas de gestão que tornaram a ineficiência da assistência aos testes para detectar a contaminação e aumento da procura por serviços de pronto atendimento. $\mathrm{O}$ que se soma aos relatos das desiguais condições de saneamento básico, abastecimento de água, moradia digna e trabalho seguro, os quais seguem como direitos negados às comunidades pesqueiras em todo o país.

No mês de maio, as inquietações voltaram-se à questão das subnotificações dos casos de contaminação e mortes, sobretudo no interior do país e na região Norte, onde não constaram nos registros oficiais. Ao final desse mesmo mês, o governo federal alterou informações oficiais, comprometeu a transparência em relação às constatações da velocidade do avanço da doença no país e o aumento exponencial da quantidade de vítimas, 
o que tornou o monitoramento comunitário, além de necessário, desafiador.

No Observatório, relatos livres narraram, em abril, os primeiros dois casos suspeitos, dois confirmados e um óbito por COVID-19 entre pescadores artesanais. No último dia de maio, somavam-se 24 casos de contaminação e 15 óbitos.

Com as manifestações graves da doença mais próximas do cotidiano das pessoas, aumentou o medo, inclusive, de procurar os serviços de saúde. Estes, rapidamente acenaram, nas regiões Norte e Sudeste, a sobrecarga e colapso, tornando-os sinônimo de sofrimento desprezado. Em algumas localidades, distantes dos centros urbanos, chegaram profissionais de saúde contaminados e, mesmo após a confirmação do diagnóstico de COVID-19, não orientaram a população, como ocorreu com comunidades indígenas e quilombolas nas regiões Norte e Nordeste do país caracterizando práticas violentas de racismo estrutural e institucional ${ }^{19}$.

De um modo geral, os conteúdos das mensagens do Observatório revelaram a importância da compreensão do caráter social da doença, iniquidades no setor público de saúde, descasos institucionais e desrespeito com quem depende exclusivamente das ações da saúde pública. Desta forma, a ecologia dos saberes se constituiu em um convite à construção compartilhada de novos saberes, ampliando horizontes de possibilidades e impulsionando o movimento propositivo.

Ações Governamentais é a segunda categoria que compõe o boletim de VPS que registra algumas das iniciativas governamentais para conter e combater o surto através das políticas públicas. A COVID-19 gerou mais demandas para as instâncias governamentais, porém, revelou a incapacidade política de apoio e assistência à grande parte da população brasileira.

Logo em março, no início da pandemia, algumas restrições sociais foram adotadas e o "fique em casa" tornou-se medida obrigatória para o bem coletivo, o que levou localidades a decretaram o distanciamento social com suspensão das atividades não essenciais, como aulas, comércio, entre outras. Praias foram interditadas, barreiras sanitárias instaladas nas entradas das cidades, restrição de deslocamentos internos e entre localidades, bem como adoção de toque de recolher em algumas localidades. A pesca artesanal foi proibida em muitas regiões, porém, liberada em seguida.

A região Nordeste destacou-se em termos de adoção de medidas protetivas à saúde da população, através do Consórcio do Nordeste, mencio- nado no Observatório como iniciativa promissora para assegurar melhores condições de vida, e por convergir decisões políticas entre governantes para a região como um todo. $\mathrm{O}$ acordo entre governos locais entrou em vigor desde fevereiro de 2020 e, para tratar da pandemia, se instituiu um Comitê Científico com produção de materiais informativos, orientações técnicas jurídicas e de saúde.

Até meados do mês de abril, o distanciamento social foi mantido pela maioria dos gestores municipais. Em seguida, precocemente, iniciouse a suspensão gradual das determinações restritivas, apesar da ascensão da contaminação, dos óbitos e da ocupação dos leitos hospitalares.

A despeito dos governos assumirem medidas de assistência à saúde, como abertura de hospitais de campanha e de novos leitos de UTI, compra de respiradores e o obrigatório uso de máscaras, para as comunidades tradicionais, as ações governamentais mantiveram-se insuficientes, ampliando a angústia da população.

Contraditoriamente às posturas iniciais e aos investimentos assistenciais, o início de maio de 2020 foi marcado pela adesão dos gestores locais à flexibilização do isolamento, mesmo diante da evolução exponencial da COVID-19. A prioridade foi redefinida para a defesa da economia em lugar da vida, como se estas fossem dimensões opostas. A doença passou, então, a se manifestar com mais intensidade entre os pobres, justamente os que enfrentaram burocratização e fragilidade dos planos de combate à pandemia. $\mathrm{O}$ relaxamento foi ampliado contrariando as recomendações da OMS.

A região Nordeste manteve as medidas de isolamento, e o Norte do país foi onde mais flexibilizou as restrições até o período analisado. A flexibilização do isolamento levou os pescadores a denunciarem o desrespeito às barreiras sanitárias e às medidas de proteção coletiva.

Os efeitos da pandemia de COVID-19 exigiram também ações coletivas de apoio mútuo e solidário. Os movimentos pesqueiros assumiram o protagonismo nos processos políticos em defesa da dignidade das comunidades e de seus trabalhadores.

A categoria ações comunitárias descreveu a capacidade do grupo de repensar e reinventar as lutas sociais, em direção à construção conjunta de estratégias de resistência específicas dos pescadores e das pescadoras, considerando a forte cultura de gerenciamento coletivo presente nas populações tradicionais, que são motivadas por saberes e práticas populares. 
As principais ações comunitárias destacaram a formação de redes de solidariedade articuladas e independentes ou em pareceria com o poder público. Em março, salientaram-se relatos sobre barreiras sanitárias comunitárias que se revelaram na restrição de acesso às localidades. Usaram correntes, pedaços de árvores, placas e pneus queimados para assegurar o fechamento das entradas e saídas aos territórios tradicionais. Em Canavieiras (BA), a população produziu um decreto comunitário sobre proteção contra o Sars-CoV-2 e contou com o apoio das instâncias governamentais para aplicá-lo.

Organizações e movimentos sociais das regiões Nordeste e Sudeste mostraram-se atuantes em iniciativas no apoio às comunidades respondendo de forma imediata as suas necessidades, como arrecadação e distribuição de alimentos e produtos de higiene aos mais pobres, redes de trocas de alimentos e venda de produtos entre membros das comunidades, além da produção de instrumentos de pressão política (ofícios, $l i$ ves, podcast etc).

Pode-se afirmar que a primeira vitória das ações de VPS no Observatório foi o Projeto de Lei 873/2020 com a inclusão legal da categoria no Auxílio Emergencial. Durante o mês de abril, destacaram-se as ações das Colônias de Pescadores e dos movimentos de pescadores na manutenção do apoio à comercialização do pescado e a realização de cadastros para o acesso aos benefícios sociais. Também, foram importantes as parcerias com alguns segmentos da imprensa na divulgação da situação de vulnerabilidade diante do avanço da COVID-19 em algumas localidades, e com Universidades, através de atividades de pesquisa e extensão.

Durante o mês de maio, realçaram-se articulações entre os movimentos pesqueiros de diferentes lugares do país. As mulheres protagonizaram ações na distribuição de alimentos, confecção e doação de máscaras faciais de proteção e, principalmente, articulação política com os movimentos nacionais e internacionais.

A organização das comunidades representa a força das lutas pesqueiras que, na atualidade, utiliza recursos tecnológicos para produção de registros em vídeos, áudios, além da participação em espaços variados que promoveram discussão sobre dilemas e desafios superados a partir da participação do grupo e da captação de recursos em editais para organizar meios de defesa e proteção das populações, territórios e da pesca artesanal. Defenderam, ainda, a organização social com foco em sustentabilidade nas práticas racistas e de violência contra a mulher.
Auxílio Emergencial é a categoria que emergiu a partir de 23 de abril. Voltou-se para o benefício social destinado aos trabalhadores informais e de baixa renda que assegura renda mínima durante a pandemia. Foram muitas as dificuldades relatadas pelos pescadores e pescadoras para compreender os critérios de elegibilidade para o cadastramento e recebimento das três parcelas previstas até o final do mês de maio, diante da escassez de informativos oficiais.

Nessa categoria, registraram-se o acompanhamento e denúncias em termos de desinformação, informações controversas, dificuldades de cadastramento e, especialmente, as aglomerações para verificação da situação cadastral do benefício nas portas das agências bancárias. Tal cenário retomou práticas assistencialistas que submetem trabalhadores a situações humilhantes, restabelecendo benesses em substituição aos direitos. Até o final do mês de abril, o tema mobilizou muitas discussões no Observatório. Em maio, quando alguns receberam o repasse, houve redução da abordagem sobre o assunto, entretanto, a todo momento relataram que havia pessoas necessitadas que não conseguirem o benefício, assim como souberam que outras, não necessitadas, receberam, a exemplo de políticos e pessoas que residiam no exterior.

\section{Conclusão}

A experiência de Vigilância Popular, com os boletins diários em um Observatório de saúde, permitiu acompanhar diversos efeitos da crise sanitária e social da COVID-19 em comunidades tradicionais de pescadores, bem como perceber a ampliação da noção de vigilância como um dos pilares centrais da saúde pública e coletiva.

Surgiram dilemas em torno de escolhas entre a contaminação e a subsistência para àqueles que têm direitos fundamentais sem garantias para os cuidados em saúde. Reafirmaram-se desigualdades sociais entre os que podem se proteger e os que precisam trabalhar.

Ao longo do primeiro mês de pandemia, manifestaram-se expectativas do enfrentamento preventivo do problema. Em seguida, veio o sofrimento com as informações de óbitos e o aumento de casos em proporções descontroladas ampliando-se as vulnerabilidades dos trabalhadores artesanais que vivem desigualdades sociais, desde muito. Pescadores sobrevivem em busca da garantia de renda mínima para evitar a fome, expostos às precárias condições de trabalho, angústias emocionais e riscos de contaminação. 
Ao mesmo tempo, a COVID-19 revelou o estrangulamento das políticas públicas, especialmente de saúde, sendo suas ações retomadas, emergencialmente, para responder à grande adversidade desta pandemia ${ }^{17,20}$.

A Vigilância Popular da Saúde mostrou pautas para os movimentos sociais que retrataram modos de vida e de trabalho específicos das comunidades pesqueiras, historicamente invisíveis. Tais pautas indicaram a necessidade de abordagens baseadas na determinação social dos processos da doença em diálogo com culturalidades considerando equidade em saúde e respeito aos simbolismos e significados cultivados pelos povos tradicionais em seus territórios sagrados.

No Observatório, as informações sobre as características das comunidades pesqueiras, as quais variam de uma região à outra, puderam ser contempladas entre os participantes. Em termos de saúde, observaram-se necessidades particulares que precisam ser incluídas nos planos terapêuticos ao levar em conta questões como ancestralidade, tradicionalidade, saberes sobre sociedade e biodiversidade.

O Observatório registrou sistematicamente denúncias de iniquidades em saúde, conflitos sociais e ambientais que marcam trabalhadores da pesca, bem como, os danos causados pelas práticas de violências racistas. O contexto da pandemia levou às decisões políticas governamentais desconectas que não diferenciam gênero, classe e raça de pessoas que estão em maior risco, e definem, assim institucionalmente quem vai adoecer e morrer. Apesar da prática estatal não conseguir proteger com dignidade a vida da população da pesca e mostrar-se incapaz de reparação, evidencia-se, a cada dia, a necessidade da retomada do Estado Democrático como indispensável ao enfrentamento das iniquidades em saúde.

O exercício da Vigilância Popular desencadeou processos emancipatórios, mesmo diante da crise sanitária. Ações solidárias se destacaram nas narrativas e revelaram a capacidade de resistência dos trabalhadores da pesca artesanal, que ao dialogarem de forma intercultural, trocaram experiências e estruturam redes de solidariedade favorecendo a organização política comunitária voltada para o combate da COVID-19.

O Observatório, dessa forma, consolida-se como espaço político de fala e escuta, com pro- dução de boletins diários que registram a potência da gestão coletiva das comunidades pesqueiras em torno dos problemas cotidianos, com possibilidades de respostas imediatas baseadas na articulação entre saberes tradicionais e recursos da modernidade.

A Vigilância Popular potencializa a ecologia de saberes ao promover diálogos prolongados entre comunidades tradicionais e acadêmicos, e, ainda, sinaliza para a emancipação social a partir de um espaço inclusivo, com estímulos à denúncia de práticas discriminatórias de racismos.

Desenvolveram-se, nessa experiência, projetos de descolonização dos saberes em defesa da democratização da saúde e do bem viver. A possibilidade de emancipação potencializa o protagonismo dos sujeitos da pesca com base em identidades coletivas e no cuidado de uns com os outros ${ }^{17}$.

Processos emancipatórios promovidos pelo Observatório ainda favorecem a formação política dos sujeitos a partir de práticas baseadas em educação popular e na solidariedade, com possibilidades de compreensão crítica do contexto pandêmico, bem como a defesa de projetos sociais como o SUS.

Como desafio, o Observatório mostrou a necessidade de denunciar fake news, assegurar a participação democrática de diversas pessoas no grupo, conciliar métodos qualitativos e quantitativos de produção de informações, bem como estabelecer parcerias, especialmente, com os Agentes Comunitários e Agentes Populares de Saúde nas localidades, atores, estes, considerados centrais para a Vigilância Popular da Saúde.

A presente análise constatou avanços do Observatório diante dos desdobramentos da plataforma, que assinalaram para possibilidades desse espaço se tornar permanente no pós-pandemia na defesa de uma política popular de saúde, assim como, observou que os boletins de VPS, instrumento deste Observatório, inspiraram a produção de informativos sobre a situação da saúde em diversas comunidades pesqueiras.

Registra-se, até a presente data, a citação do Observatório na Organização das Nações Unidas para Alimentação e Agricultura (FAO) como única ação no âmbito da pesca internacional relativo ao acompanhamento da pandemia dos pescadores na América Latina ${ }^{21}$. 


\section{Colaboradores}

AAM Trindade trabalhou na concepção, delineamento, análise dos dados, redação do artigo e aprovação da versão a ser publicada. PGL Pena trabalhou na concepção, delineamento e redação final do artigo. MAG Lima trabalhou na concepção, delineamento e revisão crítica do artigo. MCS Freitas e KL Araújo trabalharam na revisão crítica do artigo.

\section{Agradecimento}

Agradecemos aos Movimentos Sociais da Pesca, especialmente ao Conselho Pastoral dos Pescadores, por se constituírem participantes ativos na construção dos diários da pesca e dos boletins e realização da vigilância popular da COVID-19 em comunidades tradicionais. Cabe ainda enfatizar que as análises aqui realizadas foram possíveis a partir do diálogo entre as interpretações dos autores e das lideranças sociais do Movimento nas atividades do Observatório.

\section{Referências}

1. Croda J, Oliveira WK, Frutuoso RL, Mandetta LH, Baia-da-Silva DC, Brito-Souza JD, Monteiro WM, Lacerda MVG. COVID-19 in Brazil: advantages of a socialized unified health system and preparation to contain cases. Rev Soc Bras Med Trop 2020; 53

2. Organização Mundial da Saúde (OMS). Folha informativa - COVID-19. [acessado 2020 maio 12]. Disponível em: https://www.paho.org/bra/index.php?option $=$ com_content\&view $=$ article\&id $=6101: \operatorname{covid} 19$ \&Itemid $=875$.

3. Weible CM, Nohrstedt D, Cairney P, Carter DP, Crow DA, Durnova AP, Heikkila T, Ingold K, Mcconnel A, Stone D. COVID-19 e as ciências políticas: reações e perspectivas iniciais. Cienc Políticas 2020; 53(4):1-17.

4. Aquino E, Silveira IH, Pescarini J, Aquino R, SouzaFilho JA. Medidas de distanciamento social no controle da pandemia de COVID-19: Potenciais impactos e desafios no Brasil. Cien Saude Colet 2020; 25(Supl. 1):2423-2446.

5. Santos BSB. O Colonialismo e o século XXI. Outras Palavras [Internet]; 2019 jan 15 [acessado 2021 maio 23]. Disponível em: https://outraspalavras.net/geopoliticaeguerra/boaventura-o-colonialismo-e-o-seculo-xxi/.

6. Fundação Oswaldo Cruz (Fiocruz), Centro de Estudos Estratégicos. Brasil tem a segunda maior concentração de renda do mundo. [acessado 2020 maio 12]. Disponível em: https://cee.fiocruz.br.

7. El Pais. Extrema pobreza sobe e Brasil já soma13,5 milhões de miseráveis. [acessado 2020 maio 12]. Disponível em: https://brasil.elpais.com/brasil/2019/11/06/ politica/1573049315_913111.html

8. Instituto de Pesquisa Econômica Aplicada (IPEA). Número de desempregados de longo prazo cresce $42,4 \%$ em quatro anos. Brasília: IPEA; 2019. [acessado 2020 maio 12]. Disponível em: https://www.ipea.gov. $\mathrm{br} /$ portal/index.php?option $=$ com_content $\&$ view $=$ article\&id $=34817$

9. Empresa Brasileira de Comunicação (EBC). Radio Agência Nacional, COVID-19: Brasil tem novo recorde, com 751 óbitos; negros são maioria dos mortos. Rio de Janeiro: EBC; 2020. [acessado 2020 jun 15]. Disponível em: https://radioagencianacional.ebc.com.br/saude/audio/2020-05/covid-19-brasil-tem-novo-recorde-com-751-obitos-negros-sao-maioria-dos-mortos.

10. Brasil. Ministério da Saúde (MS). Mais saúde, direito de todos. Diretrizes Estratégicas. [acessado 2020 jun 5]. Disponível em: https://bvsms.saude.gov.br/bvs/ pacsaude/diretrizes.php Acesso em 05/06/2020.

11. Silva AP. Pesca artesanal brasileira. Aspectos conceituais, históricos, institucionais e prospectivos. Palmas: Embrapa Pesca e Aquicultura; 2020.

12. Pena PGL, Martins V, organizadores. Sofrimento negligenciado: doenças do trabalho em marisqueiras e pescadores artesanais. Salvador: EDUFBA; 2014.

13. Callou ABF. Povos do mar: herança sociocultural e perspectivas no Brasil. Cienc Culto 2010; 62(3):45-48.

14. Freire P. Pedagogia da autonomia: saberes necessários à prática educativa. São Paulo: Paz e Terra; 1996.

15. Minayo MCS. O desafio do conhecimento: Pesquisa qualitativa em saúde. São Paulo: Hucitec; 2013. 
16. Berkin SC, Kaltmeiero, organizadores. En diálogo. Metodologías horizontales em Ciencias Sociales y Culturales.Barcelona,España: Editorial Gedisa; 2012.

17. Santos BS. Renovar a teoria crítica e reinventar a emancipação social. São Paulo: Boitempo; 2007.

18. Nunes PA. Estudo aponta que barcos ajudaram a "espalhar" o coronavírus no interior do AM. A Crítica [acessado 2020 jun 18]; 2020 maio 22. Disponível em: https://www.acritica.com/channels/coronavirus/ news/estudo-aponta-que-barcos-ajudaram-a-espalhar-o-coranavirus-no-interior-do-am.

19. Batista WM. A inferiorização dos negros a partir do racismo estrutural. Rev Direito Prax 2018; 9(4):25812589.

20. Harvey D. Política anticapitalista em tempos de COVID-19. In: Harvey D, Zizek Slavoj, Baidou A, Davis M, Bihr A, Zibechi R. Coronavírus e a luta de classes. Cidade: Terra sem Amos; 2020.

21. Organização das Nações Unidas para Alimentação e Agricultura (FAO). Information on COVID-19 and small-scale fisheries. [cited 2020 jun 26]. Available from: http://www.fao.org/3/ca8959en/ca8959en.pdf

Artigo apresentado em 30/06/2020

Aprovado em 19/07/2021

Versão final apresentada em 21/07/2021

Editores-chefes: Romeu Gomes, Antônio Augusto Moura da Silva 